\title{
MicroRNA-26a targets the mdm2/p53 loop directly in response to liver regeneration
}

\author{
JIAN ZHOU, ZHUOYUAN LI, YINGBIN HUANG, WEIQIANG JU, \\ DONGPING WANG, XIAOFENG ZHU and XIAOSHUN HE \\ Organ Transplant Centre, The First Affiliated Hospital of Sun Yat-sen University, \\ Guangzhou, Guangdong 510080, P.R. China
}

Received November 28, 2018; Accepted May 7, 2019

DOI: $10.3892 /$ ijmm.2019.4282

\begin{abstract}
Liver regeneration (LR) is the result of a dynamic balance between the increased proliferation and decreased apoptosis of hepatocytes. However, the role of microRNA (miR)-26a in regulating complex signalling networks involving E3 ubiquitin-protein ligase Mdm2 (mdm2), p53, p21 and p27 in the process of LR is currently unclear. In the present study, it was hypothesized that miR-26a may negatively regulate the $\mathrm{mdm} 2 / \mathrm{p} 53$ signalling loop in response to LR. In vitro experiments were performed, whereby mouse liver cells were transfected with an miR-26a vector or an anti/miR-26a vector. Cell proliferation was analysed using an MTS assay and cell apoptosis, and cell cycle progression were analysed by flow cytometry. In addition, the expression of mdm2, p53, p21 and p27 were assessed using western blotting and reverse transcription-quantitative polymerase chain reaction analyses. Dual-luciferase reporter assays were also used to examine the association between mdm2 and miR-26a. A 70\% partial hepatectomy in $\mathrm{C} 57 \mathrm{BL} / 6 \mathrm{~J}$ mice was then performed, which was followed by injection with an mdm2-cDNA vector or an mdm2-small interfering RNA vector. The liver-to-body weight ratio and liver function of mice were measured at $72 \mathrm{~h}$ following vector administration. The results demonstrated an increase in hepatocyte proliferation accompanied by decreased hepatocyte apoptosis levels. In addition, inhibition of miR-26a expression was associated with a marked increase in mdm 2 expression, while the expression of p53, p21 and p27 was decreased when compared with negative controls. The opposite effects were observed when miR-26a was overexpressed. Notably, miR-26a was demonstrated to target the
\end{abstract}

Correspondence to: Dr Jian Zhou or Dr Xiaoshun He, Organ Transplant Centre, The First Affiliated Hospital of Sun Yat-sen University, 58 Zhongshan Er Road, Guangzhou, Guangdong 510080, P.R. China

E-mail: puchuanbenz@163.com

E-mail: gdtrc@163.com

Key words: mdm2, p53, negative feedback loop, microRNA, proliferation, apoptosis 3'-untranslated region of mdm2 directly. The results of the present study are the first to demonstrate as far as the authors are aware that the $\mathrm{mdm} 2 / \mathrm{p} 53$ negative feedback loop may be targeted by miR-26a directly in response to LR, and that mdm 2 negatively regulates p53, p21 and p27 but not miR-26a. miR-26a may therefore function as an important factor that regulates the interaction between mdm 2 and 553 .

\section{Introduction}

The primary function of $\mathrm{mdm} 2$ is to negatively regulate the expression and function of the p53 tumour suppressor protein. As such, high mdm2 levels decrease p53 protein levels and attenuate p53 function. In addition, studies have demonstrated that mdm 2 gene amplification and mutation of p53 are mutually exclusive (1-5). mdm 2 and p53 proteins form an autoregulatory feedback loop to tightly control proper cellular responses to various stress signals and factors, such as microRNAs (miRs). miRs are small noncoding RNAs that serve a key role in the post-transcriptional regulation of gene expression, and affect a number of cellular processes, such as cell proliferation and apoptosis. A previous study demonstrated that miR-26a serves a key role in regulating liver regeneration (LR) via direct targeting of the 3'-untranslated region (UTR) of cyclin E2 and cyclin D2 (6). In addition, decreased miR-26a enhanced mouse hepatocyte proliferation, which was accompanied by decreased levels of apoptotic hepatocytes and p53 expression (7). However, emerging evidence suggests that p53 may not be a target of miR-26a. Therefore, the authors of the present study hypothesized that additional intermediate factors may be involved in the regulation of LR by miR-26a.

The current study presents evidence to suggest that $\mathrm{mdm} 2$ may be an important potential target of miR-26a in LR, and that miR-26a may regulate $L R$ via the direct targeting of the mdm2 3'-UTR. This may result in the subsequent regulation of hepatocyte apoptosis via the $\mathrm{mdm} 2 / \mathrm{p} 53$ negative autoregulatory feedback loop. Under normal conditions, p53 protein activity is maintained at low levels by $\mathrm{mdm} 2$, as mdm2 negatively regulates the stability of p53 (8-10). Upon DNA damage, the interaction between mdm 2 and p53 is weakened by the rapid activation of p53-mediated signalling pathways, which leads to apoptosis or cell cycle arrest $(11,12)$. 
However, recent studies have demonstrated that this network may be more complex than previously thought and the current understanding of this network may be incomplete (13-15). In particular, the mechanism by which p53 escapes the mdm 2/p53 negative feedback loop and accumulates rapidly during LR is unclear. It is possible that a third factor may function to serve the $\mathrm{mdm} 2 / \mathrm{p} 53$ negative feedback loop. The aim of the present study was to investigate this further.

\section{Materials and methods}

Vector construction. Anti-miR-26a (5'-CGTGCAAGTAAC CAAGAATAGGCGTGCAAGTAACCAAGAATAGGCGTG CAAGTAACCAAGAATAGG-3') and pro-miR-26a (5'-AAG GCCGTGGCCTCGTTCAAGTAATCCAGGATAGGCTGT GCAGGTCCCAAGGGGCCTATTCTTGGTTACTTGCAC GGGGACGCGGGCCTG-3'), mdm2-cDNA (5'-GCCTCT TGCTGCTGACCACACTCCTGGTA-3') and mdm2-small interfering (si)RNA (5'-CTGCTACCGTACAGTCTCAGG CATGGACG-3') sequences were individually introduced (each, $0.6 \mu \mathrm{g} / \mu \mathrm{l}$ ) into the pShuttle IRES vector (Agilent Technologies, Inc., Santa Clara, CA, USA). Following linearization with PmeI, the pAdEasy-1 (Agilent Technologies, Inc.) and the pShuttle IRES vector were combined to generate a pAdEasy-IRES vector. 293AD cells (Cell Biolabs, Inc., San Diego, CA, USA; density, $1 \times 10^{6}$ ) (16), were subsequently transfected with the pAdEasy-IRES vector before the liquid supernatant containing viral particles was isolated and collected. The viral particles, including Ad5/anti/miR-26a, Ad5/miR-26a, Ad5/mdm2-cDNA and Ad5/mdm2-siRNA vectors were established individually.

Cell culture, transient transfection and transfection efficiency assessment. The previously established, non-primary, mouse liver cell line, nctc-1469 (American Type Culture Collection, Manassas, VA, USA) (17), was obtained from SuJi biotech company (Guangzhou, China). nctc-1469 cells were cultured in Dulbecco's modified Eagle's medium (Gibco; Thermo Fisher Scientific, Inc., Waltham, MA, USA) supplemented with $10 \%$ foetal bovine serum (Gibco; Thermo Fisher Scientific, Inc.) and maintained in a humidified atmosphere containing $5 \% \mathrm{CO}_{2}$ at $37^{\circ} \mathrm{C}$. Cells were transfected with Ad5/anti/miR-26a vector $\left(2.5 \times 10^{10} \mathrm{IU} / \mathrm{ml}\right)$ or Ad5/miR-26a vector $\left(2.5 \times 10^{10} \mathrm{IU} / \mathrm{ml}\right)$ using Lipofectamine 2000 reagent (Invitrogen; Thermo Fisher Scientific, Inc.), according to the manufacturer's protocol. To assess transfection efficiency, at 3 days following transfection of each vector into nctc-1469 cells, $1 \times 10^{6}$ cells were collected and miR-26a expression was analysed by reverse transcription-quantitative polymerase chain reaction (RT-qPCR).

Cell proliferation analysis using the MTS assay. nctc-1469 cells were first transfected with the Ad5/miR-26a vector $\left(2.5 \times 10^{10} \mathrm{IU} / \mathrm{ml}\right)$ or Ad5/anti-miR-26a vector $\left(2.5 \times 10^{10} \mathrm{IU} / \mathrm{ml}\right)$ in 24-well plates, and then re-seeded in 96-well plates at a density of 1,000 cells/well at $48 \mathrm{~h}$ following transfection. At $72 \mathrm{~h}$ following re-seeding in 96-well plates, $10 \mu \mathrm{l}$ MTS was added to the culture medium and the cells were incubated for a further $4 \mathrm{~h}$. The absorbance of each sample at $490 \mathrm{~nm}$ was read using a microplate reader (Thermo Fisher Scientific, Inc.).
Cell cycle analysis by flow cytometry. nctc-1469 cells seeded in 6-well plates at a density of $2 \times 10^{5}$ cells/well, were transfected with Ad5/miR-26a $\left(2.5 \times 10^{10} \mathrm{IU} / \mathrm{ml}\right)$ or Ad5/anti/miR-26a $\left(2.5 \times 10^{10} \mathrm{IU} / \mathrm{ml}\right)$. At $72 \mathrm{~h}$ following transfection, the cells were collected and fixed in $70 \%$ ethanol for $30 \mathrm{~min}$ at $-20^{\circ} \mathrm{C}$, and then washed twice with ice-cold PBS. The cells were centrifuged at $352 \mathrm{x}$ g for $5 \mathrm{~min}$ at $4^{\circ} \mathrm{C}$ and resuspended in RNase-containing PBS (dilution, 1:100) on ice before staining with propidium iodide at $4^{\circ} \mathrm{C}$ for $30 \mathrm{~min}$. The cells were subsequently analysed using a flow cytometer (FACSCalibur; BD Biosciences; Becton, Dickinson and Company, San Jose, CA, USA) with ModFit software (LT v3.3; Verity Software House, Inc.).

Cell apoptosis analysis by flow cytometry. nctc-1469 cells were cultured in 6-well plates and were transfected with Ad5/anti/miR-26a $\left(2.5 \times 10^{10} \mathrm{IU} / \mathrm{ml}\right)$ or Ad5/miR-26a vector $\left(2.5 \times 10^{10} \mathrm{IU} / \mathrm{ml}\right)$. At $72 \mathrm{~h}$ following transfection, the cells were collected for apoptotic analysis by flow cytometry. An Annexin V detection kit (Fermentas; Thermo Fisher Scientific, Inc.) was used to detect apoptotic cells. Data acquisition and analysis were performed using a FACSCalibur cytometer (BD Biosciences). A total of $1 \times 10^{5}$ cells were scanned for each analysis.

Surgical procedures. A total of 100 C57BL/6J male mice (age, 8 weeks; weight, 18-21 g) were purchased from the Animal Experiment Center of Sun Yat-sen University (Guangzhou, China) and raised in a pathogen-free environment maintained at $22.0 \pm 2.0^{\circ} \mathrm{C}$ with a relative humidity of $40-70 \%$. A $12 \mathrm{~h}$ light/dark cycle was implemented and mice received free access to food and water. Animals were randomly divided into 4 groups ( $\mathrm{n}=20$ /group) as follows: i) mdm2-siRNA group, $70 \%$ partial hepatectomy $(\mathrm{PH})$ in mice was performed according to the methods described by Mitchell and Willenbring (18) before the vector harbouring mdm2-siRNA $\left(0.5 \mathrm{ml} ; 2.5 \times 10^{10} \mathrm{IU} / \mathrm{ml}\right)$ was injected into liver tissues via the portal vein; ii) mdm2-cDNA group, following the $70 \% \mathrm{PH}$ procedure, mice were injected with the mdm2-cDNA vector $\left(0.5 \mathrm{ml} ; 2.5 \times 10^{10} \mathrm{IU} / \mathrm{ml}\right)$; iii) negative control (NC) group, following the $70 \% \mathrm{PH}$ procedure mice were injected with a blank vector $\left(0.5 \mathrm{ml} ; 2.5 \times 10^{10} \mathrm{IU} / \mathrm{ml}\right)$; iv) control group, the $\mathrm{PH}$ surgical procedure was performed but mice were not injected with any vectors. All mice were sacrificed at $72 \mathrm{~h}$ following the surgical procedure, and the residual liver tissues and blood samples (1.0-1.5 ml) were collected for various analyses, including in vivo transfection efficiency assessments.

Liver function tests. Following sacrifice, blood samples were collected via the postorbital venous plexus. Blood serum samples were analysed for alanine aminotransferase (ALT), aspartate aminotransferase (AST) and total bilirubin (Tbil) levels using methods described previously (19).

Liver-to-body weight ratio (LBWR). The mice were sacrificed at $72 \mathrm{~h}$ following the $\mathrm{PH}$ surgical procedure. Total body weights were first measured and then the liver tissues were resected and weighed. The ratio is presented as a percentage and calculated using the following formula: LBWR $(\%)=($ liver tissue/body weight) x100. 
Immunohistochemical staining and evaluation. Mouse liver tissues (tissue size, $\sim 0.5 \times 0.5 \times 0.2 \mathrm{~cm}^{3}$ ) were collected at $72 \mathrm{~h}$ following the $\mathrm{PH}$ surgical procedure. Samples were fixed in $4 \%$ paraformaldehyde at room temperature for $24 \mathrm{~h}$, embedded in paraffin and sliced to a thickness of $2 \mathrm{~mm}$. Immunohistochemical staining with $\mathrm{Ki}-67$ antibodies (1:200; cat. no. ab15580; Abcam) was performed to evaluate the proliferation of hepatocytes according to the manufacturer's protocol (incubated at $4^{\circ} \mathrm{C}$ overnight). Horseradish peroxidase-conjugated goat anti-rabbit IgG H\&L Secondary antibodies (1:500; cat. no. ab205718; Abcam) were then added and incubated for $20 \mathrm{~min}$ at room temperature. Proliferation index was defined as the percentage of $\mathrm{Ki}-67$ positive cells randomly counted in five high-power fields (light microscopy; magnification, x200) of each specimen.

Western blot analysis. To obtain whole-cell protein extracts, cells were first homogenised in RIPA lysis buffer (Promega Corporation, Madison, WI, USA), incubated for $30 \mathrm{~min}$ on ice and then centrifuged at room temperature for $15 \mathrm{~min}$ at $14,000 \times \mathrm{g}$. Prior to use, all buffers were treated with a protease inhibitor cocktail (Konchem Co., Ltd.). A BCA assay kit was used for protein determination (Beijing TDY Biotech Co., Ltd.). Equal quantities $(2 \mathrm{mg} / \mathrm{ml})$ of protein were separated discontinuously by $12-15 \%$ SDS-PAGE and transferred to polyvinylidene fluoride membranes (Merck KGaA, Darmstadt, Germany). Membranes were subsequently blocked with 5\% skimmed milk at room temperature for $1 \mathrm{~h}$. Antibodies (all, 1:1,000) included anti-p53 (cat. no. sc-71817), anti-mdm2 (cat. no. sc-13161), anti-p21 (cat. no. sc-53870), anti-p27 (cat. no. sc-53906; all, Santa Cruz Biotechnology, Inc., Dallas, TX, USA) and anti-GAPDH (cat. no. KC-5G4; Kangcheng, China). Immunoblots were developed using horseradish peroxidase (HRP)-conjugated anti-rabbit secondary antibodies (cat. no. Q2435; 1:2,000; Dako; Agilent Technologies, Inc.), followed by detection with immobilon western chemiluminescence HRP substrate (Merck KGaA). GAPDH was used as a referenced gene.

$R T-q P C R$. Total RNA was extracted from prepared liver cells using TRIzol (Invitrogen; Thermo Fisher Scientific, Inc.). Reagents and cDNA were synthesized according to the manufacturer's protocol (Fermentas; Thermo Fisher Scientific, Inc.). The temperature protocol of RT was as follows: $16^{\circ} \mathrm{C}$ for $30 \mathrm{~min}$, $42^{\circ} \mathrm{C}$ for $30 \mathrm{~min}$ and $85^{\circ} \mathrm{C} 5 \mathrm{~min}$. RT-qPCR was performed using a standard SYBR-Green PCR Master Mix (Toyobo Life Science, Osaka, Japan) and PCR-specific amplification was performed using the ABI7500 Applied Biosystems real-time PCR machine (Applied biosystems; Thermo Fisher Scientific, Inc.). The thermocycling conditions were as follows: $95^{\circ} \mathrm{C}$ for $5 \mathrm{~min} ; 40$ cycles at $95^{\circ} \mathrm{C}$ for $15 \mathrm{sec}, 60^{\circ} \mathrm{C}$ for $15 \mathrm{sec}$ and $72^{\circ} \mathrm{C}$ for 32 sec. The expression of miR-26a, U6, mdm2, p53, p21, p27 and GAPDH in all groups were calculated using the $2^{-\Delta \Delta C q}$ method (20). The primers used are listed in Table I. GAPDH was used as reference gene for mdm2, p53, p21 and p27 expression, and U6 was used as referenced gene for miR-26a expression. The expression of miR-26a or anti/miR-26a groups were compared with their respective control groups, and the mdm2-siRNA or mdm2-cDNA groups were compared with their respective control groups.
Table I. Primers used in reverse transcription and quantitative PCR.

\begin{tabular}{ll} 
miRNA and genes & \multicolumn{1}{c}{ Primers sequences } \\
\hline miR-26a forward & 5'-ACACTCCAGCTGGGTTCAAG \\
& TAATCCAGGATAGGC \\
miR-26a reverse & 5'-CTCAACTGGTGTCGTGGA \\
miR-26a RT & 5'-CTCAACTGGTGTCGTGGAGTC \\
& GGCAATTCAGTTGAGAGCCTATC \\
U6 forward & 5'-CTCGCTTCGGCAGCACA \\
U6 reverse & 5'-AACGCTTCACGAATTTGCGT \\
mdm2 forward & 5'-GCAGAAGAAGGCTTGGATGT \\
mdm2 reverse & 5'-GGAAGTCGATGGTTGGGAAT \\
p53 forward & 5'-GGCTCACTCCAGCTACCTGA \\
p53 reverse & 5'-TGCAGAGGCAGTCAGTCTGA \\
p21 forward & 5'-ATACCGTGGGTGTCAAAGCA \\
p21 reverse & 5'-CAGGGAGGGAGCCACAATAC \\
p27 forward & 5'-TTGGGTCTCAGGCAAACTCT \\
p27 forward & 5'-AGCAGGTCGCTTCCTCATCC \\
GAPDH forward & 5'-GTCAAGGCTGAGAACGGGAA \\
GAPDH reverse & 5'-AAATGAGCCCCAGCCTTCTC
\end{tabular}

miR, microRNA.

Dual-luciferase reporter assays. To perform the miRNA screen, the 293AD cells (Cell Biolabs, Inc.) were seeded in 96-well plates at a density of 5,000 cells/well. Following $24 \mathrm{~h}$, the cells were transiently transfected with $5 \mathrm{ng}$ of pRL/CMV (a Renilla luciferase reporter), $50 \mathrm{ng}$ of either p-LUC or p-LUC/mdm2 UTR (firefly luciferase reporter; both, Promega Corporation) together with 5 pmol of miRNA mimics using Lipofectamine 2000 (Invitrogen; Thermo Fisher Scientific, Inc.). Firefly and Renilla luciferase activities were measured at $36 \mathrm{~h}$ following transfection using a dual-luciferase reporter assay kit (Promega Corporation). Firefly luciferase activity was normalized to Renilla luciferase activity. The pRL/CMV Renilla luciferase reporter and small RNAs were simultaneously introduced into 293AD cells. These cells were collected at $36 \mathrm{~h}$ following transfection and luciferase activity was assayed using the aforementioned methods.

Statistical analysis. The results are expressed as the mean \pm standard deviation of at least three independent experiments. Statistical analysis was performed using one-way analysis of variance (followed by a post-hoc LSD test) or an independent-samples t-test. $\mathrm{P}<0.05$ was considered to indicate a statistically significant difference.

\section{Results}

Transfection efficiency of vectors. To evaluate the in vitro transfection efficiency, miR-26a expression in nctc-1469 mouse liver cells transfected with the Ad5/miR-26a, Ad5/anti/miR-26a or Ad5/blank vectors was first examined. The results demonstrated that miR-26a expression in the miR-26a group was significantly increased (3.27 \pm 0.25 ; 

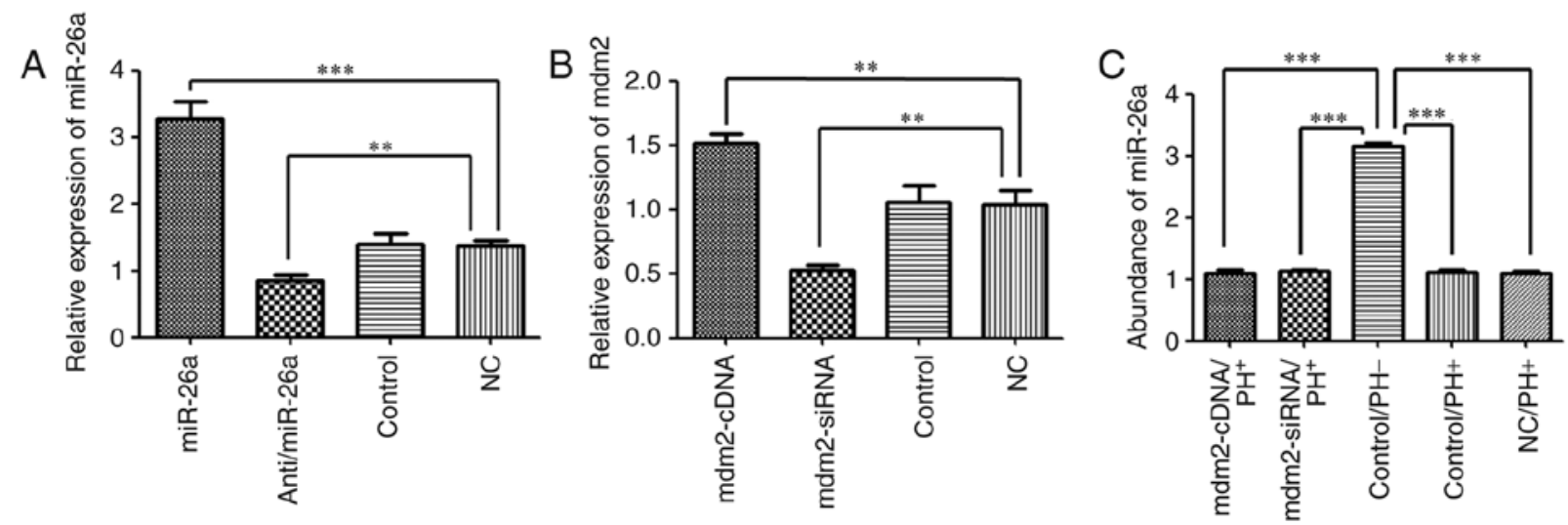

Figure 1. Transfection efficiency and abundance determination of miR-26a in vivo and in vitro. (A) Transfection efficiency and abundance of miR-26a in vitro. (B) Transfection efficiency of $\mathrm{mdm} 2$ in vivo. (C) Abundance of miR-26a and effect of mdm2 on miR-26a in vivo. ${ }^{* *} \mathrm{P}<0.01$ and ${ }^{* * *} \mathrm{P}<0.001$. miR, microRNA; mdm2, E3 ubiquitin-protein ligase Mdm2; NC, negative control; si, small interfering; $\mathrm{PH}$, partial hepatectomy.

$\mathrm{P}<0.001$ ), whereas miR-26a expression in the anti/miR-26a group was significantly decreased when compared with the NC group $(0.85 \pm 0.08$ vs. $1.36 \pm 0.09 ; \mathrm{P}<0.01)$. No significant difference in miR-26a expression between the $\mathrm{NC}$ and control groups were observed $(1.40 \pm 0.15$; Fig. $1 \mathrm{~A})$.

The expression of $\mathrm{mdm} 2$ in mice following induction of $70 \% \mathrm{PH}$ and injection with Ad5/mdm2-cDNA, Ad5/mdm2-siRNA or NC vectors in vivo was then analysed. The results demonstrated that $\mathrm{mdm} 2$ expression in the mdm2-siRNA group was significantly decreased when compared with NC group $(0.52 \pm 0.04$ vs. $1.03 \pm 0.11 ; \mathrm{P}<0.01)$. By contrast, mdm2 expression in the mdm2-cDNA group was significantly increased $(1.52 \pm 0.06 ; \mathrm{P}<0.01)$, as determined by RT-qPCR analysis. No significant difference in mdm 2 expression was observed in the NC group compared with the control group (1.06 \pm 0.12 ; Fig. 1B). These results demonstrate that the construction and transfection of the vectors in vitro and in vivo were successful.

Effect of $m d m 2$ on the relative expression of $m i R-26 a$ and detection of miR-26a abundance. To detect the abundance of miR-26a in normal liver tissues and determine the effect of mdm 2 vector transfection, the relative expression of miR-26a was analysed in vivo and in vitro. The results indicated that miR-26a expression was significantly increased in the wild-type group $(3.14 \pm 0.06 ; \mathrm{P}<0.001)$ when compared with the mdm2-cDNA group $(1.08 \pm 0.06), \mathrm{mdm} 2$-siRNA group $(1.12 \pm 0.03), \mathrm{NC}$ group $(1.09 \pm 0.03)$ and the control group $(1.11 \pm 0.04)$ in vivo. In addition, no significant difference among the four groups, apart from the wild-type group, was observed (Fig. 1C). miR-26a expression in liver cells was considered as the control group in Fig. 1A. The results demonstrated that the transfection of the vectors had no effect on the expression of miR-26a.

Effect of miR-26a on mouse hepatocyte proliferation. To investigate the effect of miR-26a on mouse hepatocyte proliferation in vitro, an MTS assay was used to detect hepatocyte proliferation. The results demonstrated that transfection of anti/miR-26a vectors significantly enhanced hepatocyte proliferation at $72 \mathrm{~h}$ following transfection when compared with the NC group $(1.56 \pm 0.05$ vs. $1.02 \pm 0.1 ; \mathrm{P}<0.001)$. By contrast, overexpression of miR-26a significantly inhibited liver cell growth $(0.58 \pm 0.07 ; \mathrm{P}<0.001)$. No observable difference in cell proliferation between the $\mathrm{NC}$ and control groups was observed (1.13 \pm 0.05 ; Fig. 2A). Cell cycle analysis revealed that the percentage of cells in G1 phase in the miR-26a group was significantly decreased compared with the NC group $(65.78 \pm 1.78 \%$ vs. $70.48 \pm 1.29 \%$; $\mathrm{P}<0.05)$. By contrast, the percentage of cells in G1 phase in the anti/miR-26a group was significantly increased $(83.81 \pm 2.47 \% ; \mathrm{P}<0.001)$. No difference in the percentage of cells in G1 phase in the $\mathrm{NC}$ and control groups were observed $(71.1 \pm 1.75 \%$; Fig. $2 \mathrm{~B}-\mathrm{F})$. Cell apoptosis analysis demonstrated that the number of apoptotic hepatocytes in the anti/miR-26a group was significantly decreased when compared with the NC group $(4.33 \pm 0.51$ vs. $6.65 \pm 0.43$; $\mathrm{P}<0.01)$, whereas the number of apoptotic cells in the miR-26a group was significantly increased $(8.65 \pm 1.02 ; \mathrm{P}<0.01)$. No difference in the number of apoptotic cells in the $\mathrm{NC}$ and

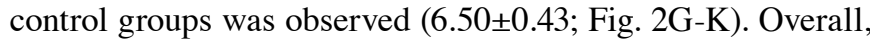
these results indicate that miR-26a may serve a key role in regulating liver cell proliferation and apoptosis.

Effect of miR-26a on the expression of $m d m 2, p 53, p 21$ and 27. To investigate the mechanism by which miR-26a modulates LR, the expression of mdm2, p53, p21 and p27 was analysed by RT-qPCR and western blotting. The results demonstrated that mdm2 expression was significantly decreased in the miR-26a group when compared with the NC group $(0.54 \pm 0.03$ vs. $1.04 \pm 0.03 ; \mathrm{P}<0.001)$, whereas $\mathrm{mdm} 2$ expression was significantly increased in anti/miR-26a group $(1.52 \pm 0.11 ; \mathrm{P}<0.001)$. No difference in $\mathrm{mdm} 2$ expression between control $(1.06 \pm 0.08)$ and NC groups were observed (Fig. 3A). p53 expression was significantly increased in the miR-26a group when compared with the NC group ( $1.3 \pm 0.09$ vs. $1.02 \pm 0.02 ; \mathrm{P}<0.001)$, whereas p53 expression was significantly decreased in the anti/miR-26a group $(0.53 \pm 0.09 ; \mathrm{P}<0.001)$. No difference in $\mathrm{p} 53$ expression between the control $(1.03 \pm 0.07)$ and $\mathrm{NC}$ groups was observed (Fig. 3B). p27 expression was significantly increased in the miR-26a group when compared with the NC group $(1.32 \pm 0.06$ vs. $1.04 \pm 0.03 ; \mathrm{P}<0.001)$, whereas the anti/miR-26a groups exhibited significantly lower p27 expression levels $(0.46 \pm 0.06$; 

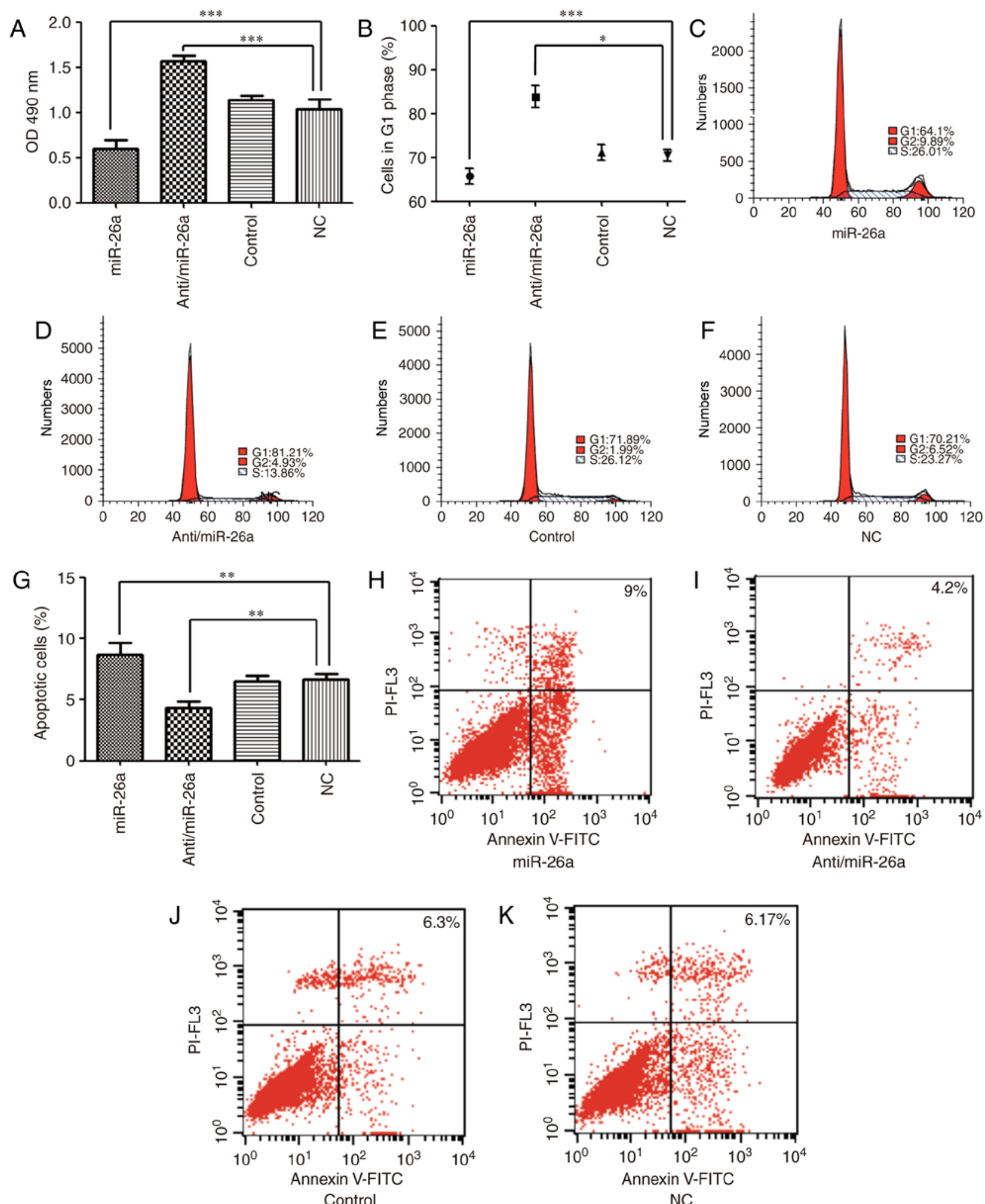

Figure 2. Effect of miR-26a on hepatocyte proliferation, cell cycle and apoptosis. (A) Cell proliferation was assessed by MTS assay at $72 \mathrm{~h}$ after transfection. (B) Cell cycle was examined by flow cytometry at $72 \mathrm{~h}$ after transfection in the (C) miR-26a group, (D) anti/miR-26a, (E) control group and (F) NC group. (G) Apoptotic cells was examined by flow cytometry at $72 \mathrm{~h}$ after transfection in the (H) miR-26a group, (I) anti/miR-26a group, (J) control group and (K) NC group. ${ }^{*} \mathrm{P}<0.05,{ }^{* *} \mathrm{P}<0.01$ and ${ }^{* * * *} \mathrm{P}<0.001$. miR, microRNA; FITC, fluorescein isothiocyanate; NC, negative control; OD, optical density.

$\mathrm{P}<0.001)$. No difference between the control $(1.02 \pm 0.07)$ and NC groups was observed (Fig. 3C). p21 expression was also significantly increased in the miR-26a group when compared with the NC group $(1.24 \pm 0.06$ vs. $1.02 \pm 0.05 ; \mathrm{P}<0.001)$, whereas the anti/miR-26a group exhibited significantly lower p21 expression levels $(0.45 \pm 0.04 ; \mathrm{P}<0.001)$. No difference between the control $(1.02 \pm 0.07)$ and $\mathrm{NC}$ groups was observed (Fig. 3D).

To identify the presence of the $\mathrm{mdm} 2 / \mathrm{p} 53$ negative feedback loop, mdm 2 and p53 expression changes were analysed. 

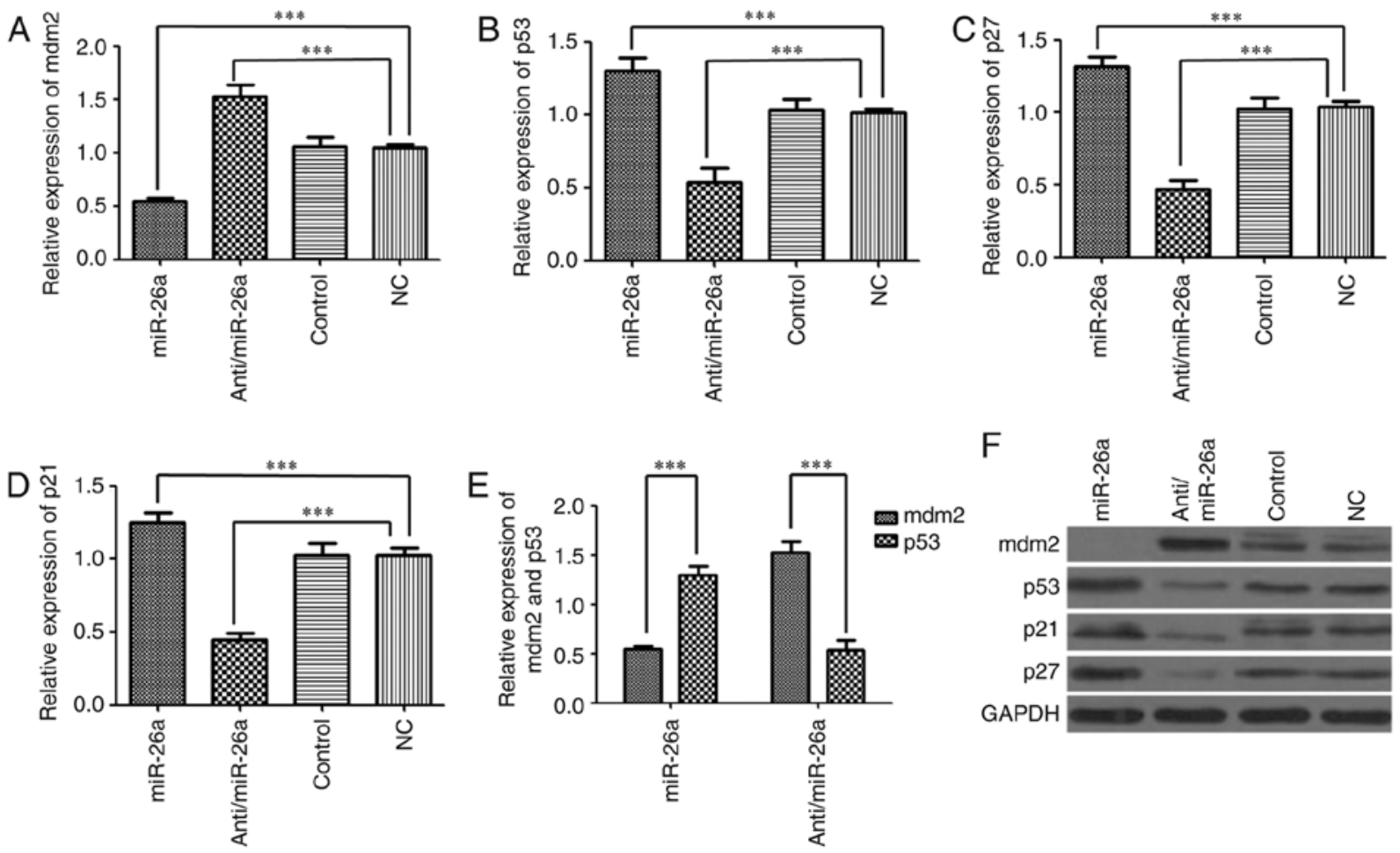

Figure 3. Effect of miR-26a on the expression of mdm2, p53, p21 and p27. (A) Relative expression of mdm2 was assessed in the miR-26a group, anti/miR-26a group, NC group and control group at $72 \mathrm{~h}$ transfection by reverse transcription-quantitative PCR. (B) P53 expression was assessed in the miR-26a group, anti/miR-26a group, NC group and control group. (C) P27 was assessed in the miR-26a group, anti/miR-26a group, NC group and control group. (D) P21 was assessed in the miR-26a group, anti/miR-26a group, NC group and control group. (E) Validation of mdm2/p53 negative feedback loop in liver regeneration by miR-26a. (F) Detection of protein levels of related genes regulated by miR-26a. GAPDH was used as loading control. ${ }^{* * * *} \mathrm{P}<0.001$. miR, microRNA; mdm2, E3 ubiquitin-protein ligase Mdm2; NC, negative control.

The results indicated that increased expression of $\mathrm{mdm} 2$ was accompanied by decreased expression of p53 $(\mathrm{P}<0.001)$, and conversely, a decrease in $\mathrm{mdm} 2$ expression was associated with increased expression of $\mathrm{p} 53(\mathrm{P}<0.001)$. This suggests that the $\mathrm{mdm} 2 / \mathrm{p} 53$ negative feedback loop may be activated in response to hepatocyte proliferation by miR-26a (Fig. 3E). Similar results were observed following western blot analysis (Fig. 3F). Collectively, these results verify the presence of the mdm2/p53 negative feedback loop, which, together with p21 and $\mathrm{p} 27$, may be regulated by miR-26a. miR-26a may therefore present a novel factor that regulates the $\mathrm{mdm} 2 / \mathrm{p} 53$ feedback loop.

miR-26a targets $m d m 2$ by directly binding to its 3 '-UTR. To elucidate the molecular mechanisms by which miR-26a leads to an accumulation of p53, putative targets of miR-26a were identified using miRanda, TargetScan and PicTar databases (21-23). The results demonstrated that the 3'-UTR of $\mathrm{mdm} 2$, a negative regulator of $\mathrm{p} 53$, contains one predicted miRNA-responsive element with regions that matched the seed sequences of miR-26a. Full-length mdm2 mRNA 3'-UTR fragments (containing wild-type and mutated miR-26a binding site sequences) were generated and inserted immediately downstream of the luciferase reporter gene. miR-26a mimics or control RNA were then co-transfected into 293AD cells with the different luciferase-3'-UTR constructs. The seed sequences (both wild-type and mutant) of the mdm2 3'-UTR are presented in Fig. 4A. A significant difference in relative luciferase activity between the miR-26a mimics group and normal control (NC) group in cells transfected with the wild-type mdm2 3'-UTR sequence was observed (4.08 \pm 0.85 vs. $7.08 \pm 0.28 ; \mathrm{P}<0.001)$. By contrast, no difference in relative luciferase activity was observed between these groups in cells transfected with the mutant mdm2 3'-UTR construct ( $3.47 \pm 0.96$ vs. $3.37 \pm 0.94$; Fig. 4 B). These results indicate that miR-26a may target mdm2 by directly binding to its 3 '-UTR.

Effect of $m d m 2$ on LR. To determine whether mdm 2 may serve a key role in LR, the effect of Ad5/mdm2-siRNA, Ad5/mdm2-cDNA and Ad5/negative control vector transfection on LR and liver function was investigated in vivo. The results demonstrated that the LBWR was significantly increased in the mdm2-cDNA group compared with NC group ( $2.83 \pm 0.27$ vs. $1.46 \pm 0.06 ; \mathrm{P}<0.001)$, whereas the LBWR was significantly decreased in the mdm2-siRNA group $(1.05 \pm 0.16 ; \mathrm{P}<0.05)$. No difference in LBWR was observed between the control $(1.55 \pm 0.15)$ and $\mathrm{NC}$ groups (Fig. 5A). At the same time, the Ki-67 index was significantly increased in the mdm2-cDNA group when compared with NC group $(76.96 \pm 1.6$ vs. $56.86 \pm 1.56 ; \mathrm{P}<0.001)$, whereas the Ki-67 was significantly decreased in the mdm2-siRNA group (30.5 \pm 0.81 ; $\mathrm{P}<0.001)$. No difference in Ki-67 was observed between the control (56.9 \pm 1.05$)$ and $\mathrm{NC}$ groups (Fig. 5B). AST levels were significantly decreased in the mdm2-cDNA group compared with the NC group $(320 \pm 20$ vs. $419 \pm 9 ; \mathrm{P}<0.01)$, whereas AST levels were significantly increased in the mdm2-siRNA group $(503 \pm 61 ; \mathrm{P}<0.05)$. No difference in AST levels between the control (412 \pm 11$)$ and $\mathrm{NC}$ groups was observed (Fig. 5C). ALT 
A

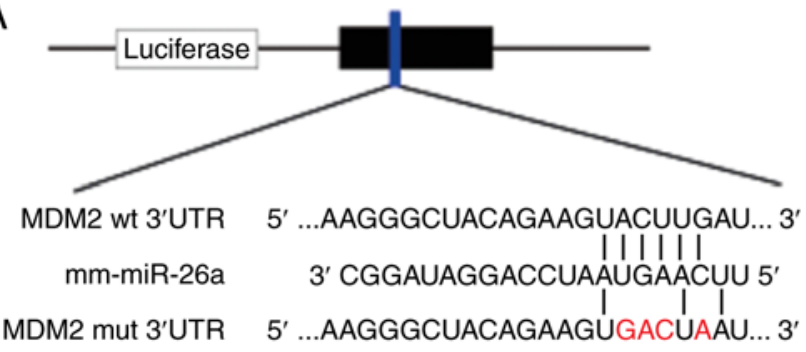

B

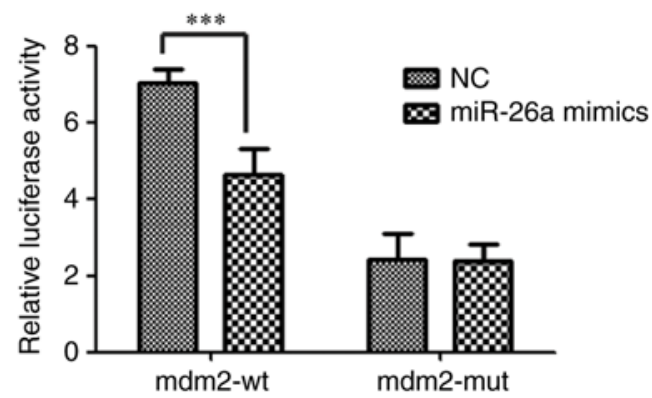

Figure 4. miR-26a directly targets the 3'-UTR of mdm2. (A) The seed sequences (both wild-type and mutant) of the 3'-UTR of mdm2. (B) Relative luciferase activity assays of mdm2 3 '-UTR (both wt and mut) luciferase reporters after co-transfection with miR-26a mimics or normal control. ${ }^{* * * *} \mathrm{P}<0.001$. miR, microRNA; mdm2, E3 ubiquitin-protein ligase Mdm2; NC, negative control; UTR, untranslated region; wt, wild-type; mut, mutant.
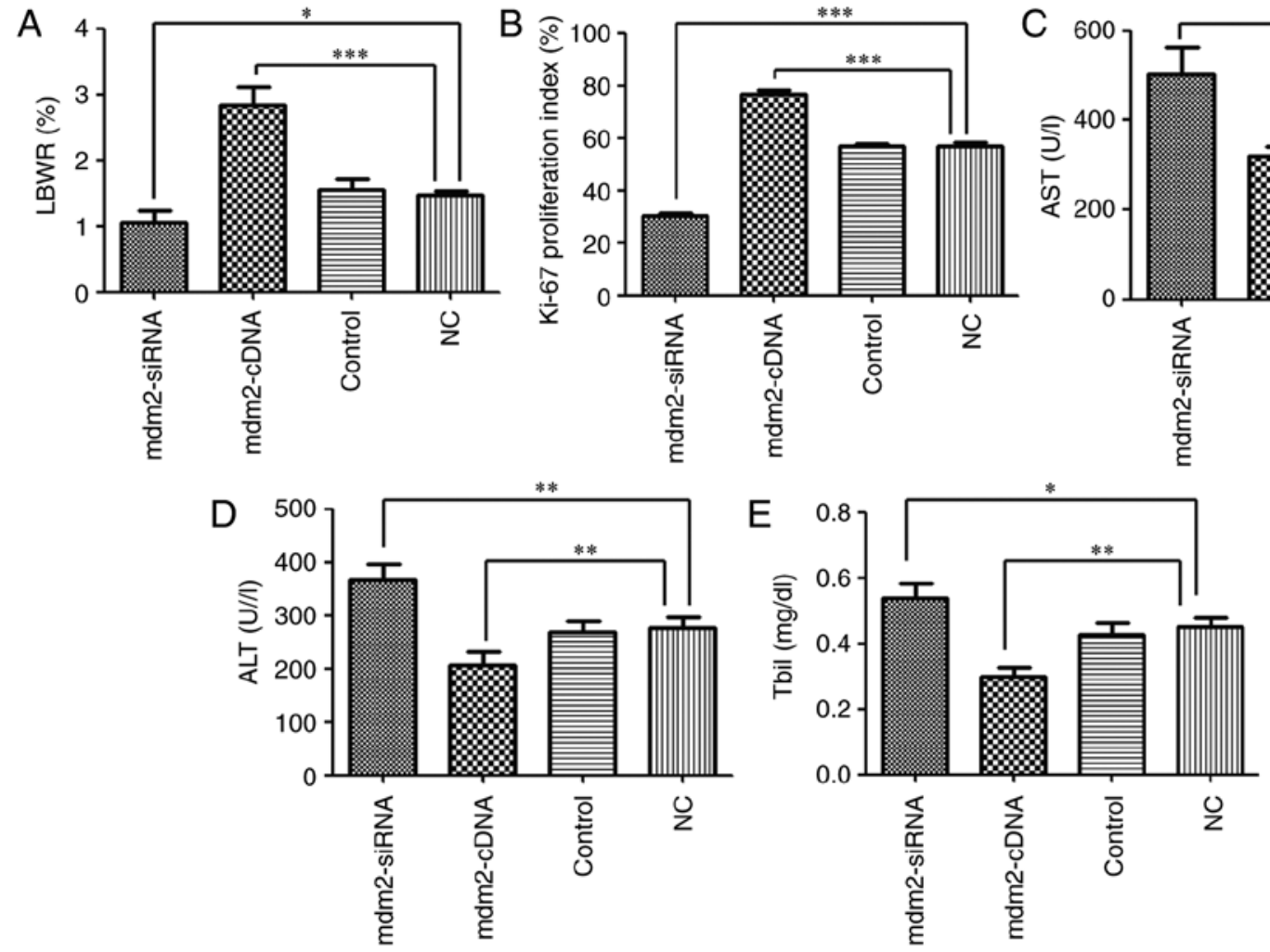

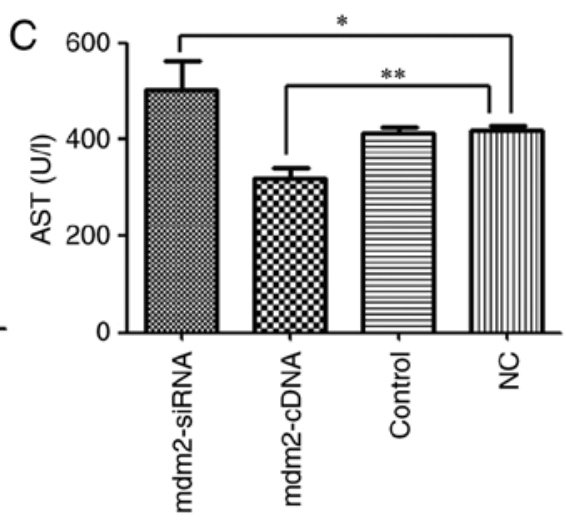

Figure 5. Effect of mdm2 on liver regeneration. (A) Liver-to-body weight ratio was assessed in mdm2-cDNA group, mdm2-siRNA group, NC group and control group. (B) The Ki-67 proliferation index following 70\% partial hepatectomy in mdm2-cDNA group, mdm2-siRNA group, NC group and control group. (C) AST was tested in mdm2-cDNA group, mdm2-siRNA group, NC group and control group. (D) ALT was tested in mdm2-cDNA group, mdm2-siRNA group, NC group and control group. (E) Tbil was assessed in mdm2-cDNA group, mdm2-siRNA group, NC group and control group. ${ }^{*} \mathrm{P}<0.05$, ${ }^{* *} \mathrm{P}<0.01$ and ${ }^{* * * *} \mathrm{P}<0.001$. miR, microRNA; mdm2, E3 ubiquitin-protein ligase Mdm2; NC, negative control; si, small interfering; Tbil, total bilirubin; ALT, alanine aminotransferase; AST, aspartate aminotransferase.

levels were significantly decreased in the mdm2-cDNA group compared with the NC group $(206 \pm 25$ vs. $277 \pm 18 ; \mathrm{P}<0.01)$, whereas ALT levels were significantly increased in the mdm2-siRNA group $(367 \pm 30 ; \mathrm{P}<.01)$. No difference between the control (268 \pm 21$)$ and $\mathrm{NC}$ group was observed (Fig. 5D). Tbil was significantly decreased in the mdm2-cDNA group compared with the NC group $(0.29 \pm 0.03$ vs. $0.45 \pm 0.03$; $\mathrm{P}<0.01$ ), whereas Tbil was significantly increased in the mdm2-siRNA group $(0.53 \pm 0.04 ; \mathrm{P}<0.05)$. No difference between the control $(0.42 \pm 0.03)$ and $\mathrm{NC}$ groups were observed (Fig. 5E). Collectively, these results indicate that $\mathrm{mdm} 2$ serves a key role in LR.
Effect of $m d m 2$ on the p53 network and miR-26a expression. To investigate the effect of $\mathrm{mdm} 2$ on the p53 network and miR-26a expression, the expression levels of p53, p21, p27 and miR-26a following transfection with Ad5/mdm2-siRNA, Ad5/mdm2-cDNA vector or NC was examined in vitro. The results demonstrated that p53 expression was significantly decreased in the mdm2-cDNA group compared with the $\mathrm{NC}$ group $(0.58 \pm 0.08$ vs. $0.84 \pm 0.04 ; \mathrm{P}<0.001)$, whereas increased p53 expression was observed in the mdm2-siRNA group $(1.3 \pm 0.11 ; \mathrm{P}<0.001)$. No difference between the control $(0.88 \pm 0.06)$ and $\mathrm{NC}$ groups were observed (Fig. 6A). p21 expression was significantly decreased in the mdm2-cDNA group 

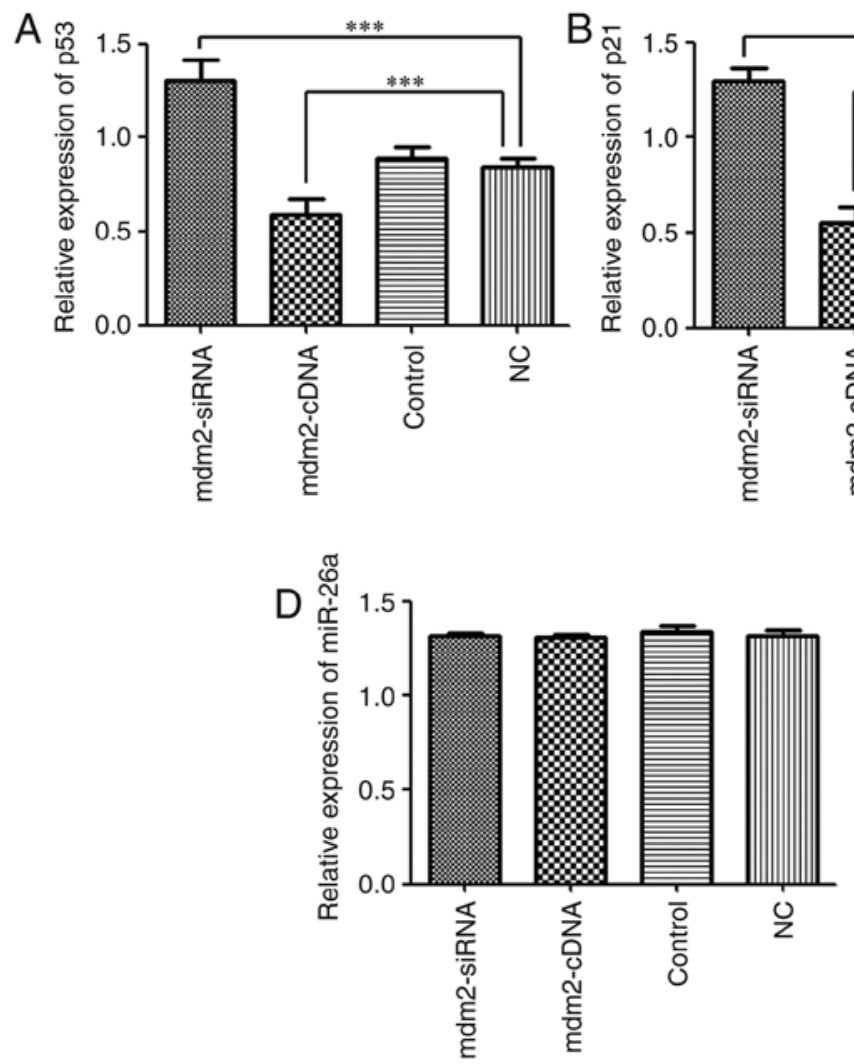

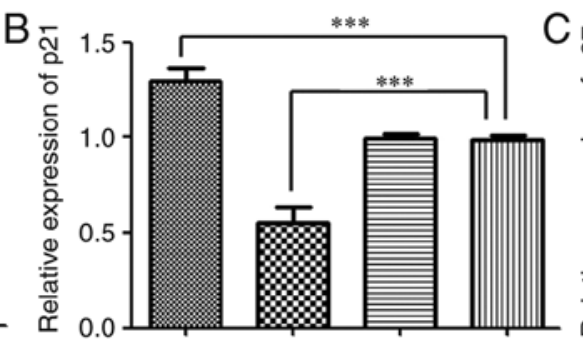

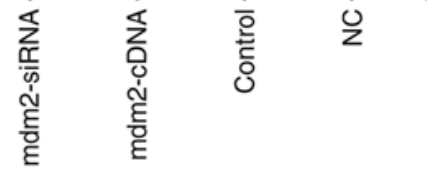

E

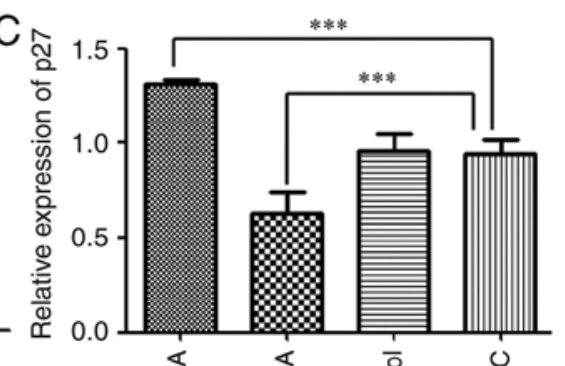

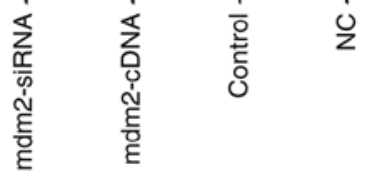

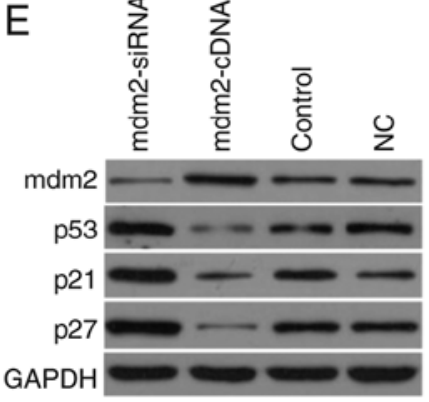

GAPDH

Figure 6. Effect of mdm2 on p53 network and miR-26a expression. (A) Expression of p53 was assessed in mdm2-cDNA group, mdm2-siRNA group, NC group and control group by reverse transcription-quantitative PCR. (B) Expression of p21 was assessed in mdm2-cDNA group, mdm2-siRNA group, NC group and control group. (C) Expression of p27 was assessed in mdm2-cDNA group, mdm2-siRNA group, NC group and control group. (D) miR-26a was assessed in mdm2-cDNA group, mdm2-siRNA group, NC group and control group. (E) Protein level of p53, p21 and p27 was assessed by western blotting. GAPDH was used as a loading control. ${ }^{* * *} \mathrm{P}<0.001$. miR, microRNA; mdm2, E3 ubiquitin-protein ligase Mdm2; NC, negative control; si, small interfering.

when compared with the NC group $(0.55 \pm 0.08$ vs. $0.99 \pm 0.02$; $\mathrm{P}<0.001)$, whereas a significant increase in $\mathrm{p} 21$ expression was observed in the mdm2-siRNA group $(1.29 \pm 0.06 ; \mathrm{P}<0.001)$. No difference between the control $(0.99 \pm 0.02)$ and $\mathrm{NC}$ groups was observed (Fig. 6B). p27 expression was significantly decreased in the mdm2-cDNA group when compared with the NC group $(0.62 \pm 0.11$ vs. $0.94 \pm 0.07 ; \mathrm{P}<0.001)$, whereas a significant increase in p27 expression was observed in the mdm2-siRNA group $(1.31 \pm 0.02 ; \mathrm{P}<0.001)$. No difference between the control $(0.95 \pm 0.09)$ and NC groups was observed (Fig. 6C). The expression of miR-26a among all experimental groups was not statistically different (Fig. 6D). Consistent with these observations, the same expression patterns were observed following western blot analysis (Fig. 6E). Collectively, these results suggest that $\mathrm{mdm} 2$ exerts a negative regulatory effect on $\mathrm{p} 53$, p21 and p27, but not miR-26a.

\section{Discussion}

It is known that miRs bind to partially complementary sites in the 3'-UTRs of target genes, which leads to the translational repression of target genes. To date, several miRs that target mdm 2 have been identified, including miR-25, miR-605, miR-32, and miR-143/145 (24-26). miR-605 has also been identified as a transcriptional target of p53, and it was demonstrated that overexpression of miR-605 directly reduces mdm 2 levels and enhances p53 function (26). The results of the current study also demonstrate that overexpression of miR-26a directly decreases mdm 2 levels and promotes p53 function. Therefore, these miRs form feedback loops with $\mathrm{mdm} 2 / \mathrm{p} 53$ to decrease $\mathrm{mdm} 2$ protein levels and promote $\mathrm{p} 53$ function. Although each cellular response, including cell cycle arrest, apoptosis, DNA repair and senescence, has its own detector and signalling pathway, each involves a common factor; the mdm 2 protein. Positive or negative regulation of the $\mathrm{mdm} 2$ protein in turn regulates p53 levels.

To investigate the importance of mdm 2 activation in LR in the current study, a $70 \% \mathrm{PH}$ mouse model was generated and mice were injected with Ad5/mdm2-siRNA or Ad5/mdm2-cDNA vectors. The results demonstrated that mdm 2 serves a key role in promoting LR. mdm 2 was originally identified in a spontaneously transformed mouse $3 \mathrm{~T} 3$ cell line (27). Its role has become central to its putative function as an oncogene. mdm 2 has been extensively described as a physiologic antagonist of p53, as it binds the N-terminal of p53 and blocks the transactivation domain required for $\mathrm{p} 53$ transcriptional activity $(8,28)$. When activated, p53 positively regulates $\mathrm{mdm} 2$ gene expression (11). However, mdm 2 appears to exert a broader biological role. A number of recent studies investigating the effect of $\mathrm{mdm} 2$ overexpression in cell lines have demonstrated that $\mathrm{mdm} 2$ may be antiproliferative under certain circumstances $(29,30)$.

It is well established that multiple cellular stresses can disrupt the mdm2/p53 interaction. Proteins involved in the 
DNA damage response enhance p53 stability and activation through a series of post-translational modifications on $\mathrm{mdm} 2$ and p53 (31,32). mdm2 is encoded by genes that are responsive to p53 transactivation (33-35) and promotes the growth of normal cells to maintain sufficient cell numbers in specific adult tissues by inhibiting p53 activity. Several transfection studies have revealed that the mdm 2 protein binds to the $\mathrm{p} 53$ transcription factor and sequesters it from p53 target gene promoters in vitro $(8,36,37)$. The present study investigated the effect miR-26a on mdm 2 and p53 and subsequent hepatocyte proliferation, and the results indicated that the $\mathrm{mdm} 2 / \mathrm{p} 53$ negative feedback loop was activated in response to hepatocyte proliferation by miR-26a.

Studies have demonstrated that $\mathrm{p} 53$ regulates the growth of mammalian cells by altering the expression of numerous genes that affect cellular proliferation, apoptosis, metabolism and senescence $(38,39)$. Given that p53 affects a number of different cellular functions directly and indirectly involved in cell growth, p53 has been termed the 'guardian of the genome', as it functions as a tumour suppressor and prevents the transmission of mutations to subsequent generations of cells (40-42). p21, a potent cyclin-dependent kinase (CDK) inhibitor, is one of the most well-studied downstream target genes of p53 (43), It was reported that enhanced expression of p21 and p27 proteins leads to cell cycle arrest in the G1 phase by inhibiting CDK1, CDK2 and CDK4/6 (44-47). Cell cycle progression is primarily controlled by activation of several CDKs, which is also modulated by p21, p27 and p53 (48). In addition, increased expression of p53 enhances p 21 expression (49). The results of the present study demonstrated that p53, p21 and p27 expression was positively correlated with miR-26a expression in LR, but negatively correlated with mdm 2 expression. In addition, $\mathrm{mdm} 2$ negatively regulates $\mathrm{p} 53$, p21 and p27, but not miR-26a.

There are two limitations of the current study. Firstly, primary hepatocytes were not used for the in vitro experiments. Secondly, only one cell line was used in the present study. Results from several hepatocyte cell lines would increase the current understanding of the effects of miR-26a on hepatocyte proliferation. However, it should be noted that all in vivo results were consistent with the major in vitro observations.

In conclusion, the results of the current study are the first to demonstrate that the mdm2/p53 negative feedback loop may be targeted by miR-26a directly in response to LR, and mdm2 exerts a negative regulatory effect on p53, p21 and p27, but not miR-26a. miR-26a may present a novel factor that regulates the $\mathrm{mdm} 2 / \mathrm{p} 53$ feedback loop. These results provide a novel insight into the role of miR-26a in p53-mediated regulation of LR.

\section{Acknowledgements}

Not applicable.

\section{Funding}

The present study was supported by grants from the Ph.D. Programs Foundation of Ministry of Education of China (grant. no. 20130171120076), the National Natural
Science Foundation of China (grant. no. 81400655), the Natural Science Foundation of Guangdong Province (grant. no. 2015A030313023) and the Science and Technology Project of Guangdong Province (grant. no. 2017A020215166).

\section{Availability of data and materials}

All data used and/or analysed during the present study are available from the corresponding author on reasonable request.

\section{Authors' contributions}

JZ made substantial contributions to the design of this study and wrote the manuscript. JZ, ZL, YH and WJ performed experiments. DW and $\mathrm{XZ}$ performed data analysis. JZ and $\mathrm{XH}$ interpreted the data. JZ, XZ and XH revised the critically. All authors read and approved the final manuscript and agreed to the publication of the final manuscript.

\section{Ethics approval and consent to participate}

All experimental protocols involving animals were approved by the Ethics Committee of the First Affiliated Hospital of Sun Yat-sen University (Guangzhou, China).

\section{Patient consent for publication}

Not applicable.

\section{Competing interests}

The authors declare that they have no competing interests.

\section{References}

1. Port JD and Sucharov C: Role of microRNAs in cardiovascular disease: Therapeutic challenges and potentials. J Cardiovasc Pharmacol 56: 444-453, 2010.

2. Lynn FC: Meta-regulation: MicroRNA regulation of glucose and lipid metabolism. Trends Endocrinol Metab 20: 452-459, 2009.

3. Pager CT, Wehner KA, Fuchs $G$ and Sarnow P: MicroRNA-mediated gene silencing. Prog Mol Biol Transl Sci 90: 187-210, 2009.

4. Hammond SM: MicroRNA therapeutics: A new niche for antisense nucleic acids. Trends Mol Med 12: 99-101, 2006.

5. He L and Hannon GJ: MicroRNAs: Small RNAs with a big role in gene regulation. Nat Rev Genet 5: 522-531, 2004.

6. Zhou J, Ju QW, Yuan XP, Zhu XF, Wang DP and He XS: miR-26a regulates mouse hepatocyte proliferation via directly targeting their 3'untranslated region of CCND2 and CCNE2. Hepatobiliary Pancreat Dis Int 15: 65-72, 2016.

7. Zhou J, Ju W, Wang D, Wu L, Zhu X, Guo Z and He X: Down-regulation of microRNA-26a promotes mouse hepatocyte proliferation during liver regeneration. PLoS One 7: e33577, 2012.

8. Momand J, Zambetti GP, Olson DC, George D and Levine AJ: The mdm-2 oncogene product forms a complex with the p53 protein and inhibits p53-mediated transactivation. Cell 69: 1237-1245, 1992

9. Haupt Y, Maya R, Kazaz A and Oren M: Mdm2 promotes the rapid degradation of p53. Nature 387: 296-299, 1997.

10. Eischen CM and Lozano G: p53 and MDM2: Antagonists or partners in crime? Cancer Cell 15: 161-162, 2009.

11. Barak Y, Juven T, Haffner R and Oren M: Mdm2 expression is induced by wild-type p53 activity. EMBO J 12: 461-468, 1993.

12. Harris SL and Levine AJ: The p53 pathway: Positive and negative feedback loops. Oncogene 24: 2899-2908, 2005. 
13. Cao LQ, Wang YN, Liang M and Pan MZ: CALB1 enhances the interaction between 553 and MDM2, and inhibits the senescence of ovarian cancer cells. Mol Med Rep 19: 5097-5104, 2019.

14. Xu X, Liu Q, Zhang C, Ren S, Xu L, Zhao Z, Dou H, Li P, Zhang X, Gong Y and Shao C: Inhibition of DYRK1A-EGFR axis by p53-MDM2 cascade mediates the induction of cellular senescence. Cell Death Dis 10: 282, 2019.

15. Wurz RP and Cee VJ: Targeted degradation of MDM2 as a new approach to improve the efficacy of MDM2-p53 inhibitors. J Med Chem 62: 445-447, 2019.

16. Shunchang S, Haitao C, Weidong $\mathrm{C}$, Jingbo $\mathrm{H}$ and Yunsheng P: Expression of truncated dystrophin cDNAs mediated by a lentiviral vector. Neurol India 56: 52-56, 2008.

17. Guo J, Li M, Meng X, Sui J, Dou L, Tang W, Huang X, Man Y, Wang S and Li J: miR-291b-3p induces apoptosis in liver cell line NCTC1469 by reducing the level of RNA-binding protein HuR. Cell Physiol Biochem 33: 810-822, 2014.

18. Mitchell $\mathrm{C}$ and Willenbring $\mathrm{H}$ : A reproducible and well-tolerated method for $2 / 3$ partial hepatectomy in mice. Nat Protoc 3 $1167-1170,2008$

19. Bockhorn M, Goralski M, Prokofiev D, Dammann P, Grünewald P, Trippler M, Biglarnia A, Kamler M, Niehues EM, Frilling A, et al: VEGF is important for early liver regeneration after partial hepatectomy. J Surg Res 138: 291-299, 2007.

20. Livak KJ and Schmittgen TD: Analysis of relative gene expression data using real-time quantitative PCR and the 2(-Delta Delta C(T)) method. Methods 25: 402-408, 2001.

21. Grimson A, Farh KK, Johnston WK, Garrett-Engele P, Lim LP and Bartel DP: MicroRNA targeting specificity in mammals: Determinants beyond seed pairing. Mol Cell 27: 91-105, 2007.

22. Betel D, Wilson M, Gabow A, Marks DS and Sander C: The microRNA.org resource: Targets and expression. Nucleic Acids Res 36 (Database issue): D149-D153, 2008

23. Krek A, Grün D, Poy MN, Wolf R, Rosenberg L, Epstein EJ, MacMenamin P, da Piedade I, Gunsalus KC, Stoffel M and Rajewsky N: Combinatorial microRNA target predictions. Nat Genet 37: 495-500, 2005.

24. Zhang J, Sun Q, Zhang Z, Ge S, Han ZG and Chen WT: Loss of microRNA-143/145 disturbs cellular growth and apoptosis of human epithelial cancers by impairing the MDM2-p53 feedback loop. Oncogene 32: 61-69, 2013.

25. Suh SS, Yoo JY, Nuovo GJ, Jeon YJ, Kim S, Lee TJ, Kim T, Bakàcs A, Alder H, Kaur B, et al: MicroRNAs/TP53 feedback circuitry in glioblastoma multiforme. Proc Natl Acad Sci USA 109: 5316-5321, 2012.

26. Xiao J, Lin H, Luo X and Wang Z: miR-605 joins p53 network to form a p5:miR-605:Mdm2 positive feedback loop in response to stress. EMBO J 30: 524-532, 2011.

27. Cahilly-Snyder L, Yang-Feng T, Francke U and George DL: Molecular analysis and chromosomal mapping of amplified genes isolated from a transformed mouse 3 T3 cell line. Somat Cell Mol Genet 13: 235-244, 1987.

28. Chen J, Wu X, Lin J and Levine AJ: Mdm-2 inhibits the G1 arrest and apoptosis functions of the p53 tumor suppressor protein. Mol Cell Biol 16: 2445-2452, 1996.

29. Brown DR, Thomas CA and Deb SP: The human oncoprotein MDM2 arrests the cell cycle: Elimination of its cell-cycle-inhibitory function induces tumorigenesis. EMBO J 17: 2513-2525, 1998.

30. Dang J, Kuo ML, Eischen CM, Stepanova L, Sherr CJ and Roussel MF: The RING domain of Mdm2 can inhibit cell proliferation. Cancer Res 62: 1222-1230, 2002.
31. Wade M, Wang YV and Wahl GM: The p53 orchestra: Mdm2 and Mdmx set the tone. Trends Cell Biol 20: 299-309, 2010.

32. Kruse JP and Gu W: Modes of p53 regulation. Cell 137: 609-622, 2009.

33. Juven T, Barak Y, Zauberman A, George DL and Oren M: Wild-type p53 can mediate sequence-specific transactivation of an internal promoter within the $\mathrm{mdm} 2$ gene. Oncogene 8: 3411-3416, 1993

34. Wu X, Bayle JH, Olson D and Levine AJ: The p53-mdm-2 autoregulatory feedback loop. Genes Dev 7: 1126-1132, 1993.

35. Phillips A, Teunisse A,Lam S,Lodder K, Darley M,Emaduddin M, Wolf A, Richter J, de Lange J, Verlaan-de Vries M, et al: HDMX-L is expressed from a functional p53-responsive promoter in the first intron of the HDMX gene and participates in an autoregulatory feedback loop to control p53 activity. J Biol Chem 285: 29111-29127, 2010

36. Oliner JD, Pietenpol JA, Thiagalingam S, Gyuris J, Kinzler KW and Vogelstein B: Oncoprotein MDM2 conceals the activation domain of tumour suppressor p53. Nature 362: 857-860, 1993.

37. Chen J, Lin J and Levine AJ: Regulation of transcription functions of the p53 tumor suppressor by the $\mathrm{mdm}-2$ oncogene. Mol Med 1: 142-152, 1995.

38. Vousden KH and Lu X: Live or let die: The cell's response to p53. Nat Rev Cancer 2: 594-604, 2002.

39. Vousden KH and Ryan KM: p53 and metabolism. Nat Rev Cancer 9: 691-700, 2009.

40. Lane DP: Cancer. p53, guardian of the genome. Nature 358: $15-16,1992$

41. Soussi T and Béroud C: Assessing TP53 status in human tumours to evaluate clinical outcome. Nat Rev Cancer 1: 233-240, 2001

42. Hollstein M, Sidransky D, Vogelstein B and Harris CC: p53 mutations in human cancers. Science 253: 49-53, 1991.

43. Deng J, Yang M, Jiang R, An N, Wang X and Liu B: Long non-coding RNA HOTAIR regulates the proliferation, self-renewal capacity, tumor formation and migration of the cancer stem-like cell (CSC) subpopulation enriched from breast cancer cells. PLoS One 12: e0170860, 2017.

44. Nakae J, Kitamura T, Kitamura Y, Biggs WH III, Arden KC and Accili D: The forkhead transcription factor Foxol regulates adipocyte differentiation. Dev Cell 4: 119-129, 2003.

45. Dijkers PF, Medema RH, Pals C, Banerji L, Thomas NS, Lam EW, Burgering BM, Raaijmakers JA, Lammers JW, Koenderman L and Coffer PJ: Forkhead transcription factor FKHR-L1 modulates cytokine-dependent transcriptional regulation of p27(KIP1). Mol Cell Biol 20: 9138-9148, 2000

46. Ezhilarasan D, Evraerts J, Sid B, Calderon PB, Karthikeyan S, Sokal E and Najimi M: Silibinin induces hepatic stellate cell cycle arrest via enhancingp53/p27 and inhibiting Akt downstream signaling protein expression. Hepatobiliary Pancreat Dis Int 16: 80-87, 2017.

47. Gartel AL and Radhakrishnan SK: Lost in transcription: p21 repression, mechanisms, and consequences. Cancer Res 65 3980-3985, 2005.

48. Hofseth LJ, Hussain SP and Harris CC: p53: 25 years after its discovery. Trends Pharmacol Sci 25: 177-181, 2004.

49. Saile B, Matthes N, El Armouche H, Neubauer K and Ramadori G: The bcl, NFkappaB and p53/p21WAF1 systems are involved in spontaneous apoptosis and in the anti-apoptotic effect of TGF-beta or TNF-alpha on activated hepatic stellate cells. Eur J Cell Biol 80: 554-561, 2001 